\title{
AN INTRODUCTION TO MAPPING METHODS AS USED IN MAP COMPILATION FROM AERIAL PHOTOGRAPHS
}

\author{
by F. R. WrLcox
}

New York State Ranger School 1921. Instructor N. Y. State Ranger School. Forester Spruce Falls Paper Co. Ltd. Kapuskasing, Ont. Division Forester, Canadian Internnional Paper Co. Ltd. 1925 to date, Maniwaki, Que.

There is nothing new about the fundamental principles involved in map preparation from aerial photographs. These principles were first introduced in terrestial photographic surveying in 1845 by the French and long before the first aircraft limped off the ground under the guiding hand of Wilbur Wright in 1903, all the fundamentals we are now using were highly developed.

It is true, however, that only recently have aerial photographs become familiar to the forester. Canada can, without dispute, claim credit for much of the original work, both in the early developments of photographic mapping procedure and in its more recent practical adaptation to the preparation of precise topographic maps and the less accurate, but consistently so, forest maps. The late E. G. Deville, Surveyor General of Canada was one of the pioneers in the field. He developed the first stereoscopic plotting machine in 1908. In spite of its simplicity, this machine had certain disadvantages. Nevertheless the principles used are the basis for at least two of the present day plotting machines.

Another pioneer was Ellwood Wilson, Forest Engineer, with the Laurentide Company who, in 1919 first appreciated the value and foresaw the possibility of aerial photographs in the execution of forest management.

Turning to more recent developments, it was the Topographical Surveys of Canada, under the able direction of A.M. Narraway, who developed the grid method of mapping from obliques which has come to be known as the Canadian Method.

All mapping methods and procedures as known and developed up to the present time are based on the one fundamental fact viz: All radial angles measured on the photograph from the optical centre or principal point to any image points are equal and angle true to the same angles measured on the. ground. This axium holds true irrespective of difference in elevation of the ground points. A careful study of figure one will make this fundamental element of 
all vertical photographs clearly understood. There are various accepted procedures utilizing this principal. All can be grouped under four main headings, viz:

1. THE RADIAL LINE METHOD

The student of Photogram metry should first master this method insomuch as a thorough understanding of its elements simplifies the study of all other solutions and methods now in commercial use.

The inventor of the plane table,

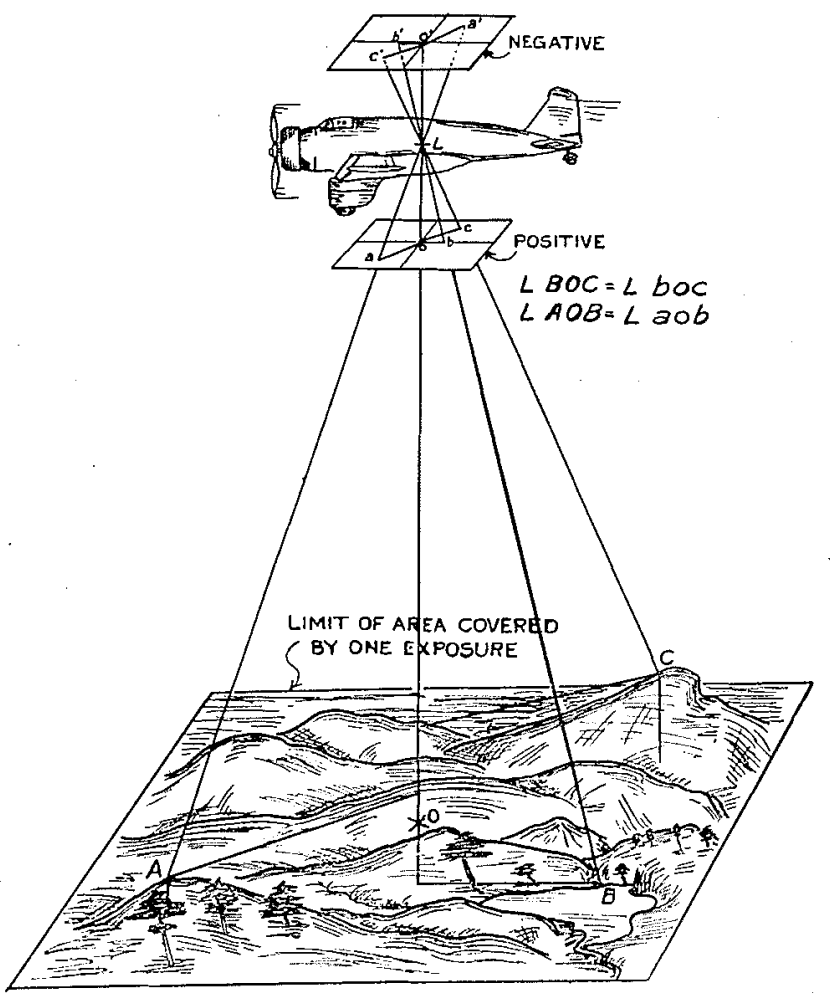

FIG.I whoever he was, and the well known "Three Point Problem" should possibly receive credit as the originator of the solution of aerial mapping by the radial line method. Its first use was undoubtedly in the United States about 1898, utilizing photographs taken from balloons. The radial line method has much in common with the use of the plane table.

One of the first economic uses of the method was a British Army exercise (1928) carried out near Arundel. For this reason the radial line method is also known, particularly in British Military Departments, as the Arundel Method. The results of the Arundel experiments, are published in detail in Professional Papers Nos. 3, 4 and 6 of the Air Survey Committee of Great Britain. These papers are available at H.M.S. Stationery Office London, England. They make an excellent reference for student use. The Arundel method refers particularly to the use of the radial line procedure in preparing contour maps. Major Bagley of the U.S. Army Corps of Engineers did much of the original work in developing the radial line method. 


\section{THE MOSAIC METHOD}

The Mosaic method takes liberal advantage of the angle true element of vertical photographs but does not actually require an understanding of it. In its crudest form the Mosaic map is built by matching identical features as they appear on succeeding photographs and then glueing the photographs together.

The precise Mosaic requires the correction of individual photographs for tilt and scale, and a more refined matching process. The corrections referred to are accomplished by an operation termed "rectifying" which consists of rephotographing the negative in the laboratory while correcting for scale and tilt. The section of each photograph used is carefully selected and the prints are evenly toned during the developing process.

The field of use for the Mosaic, can be defined best by quoting from the writings of one of the most prominent authorities on aerial photographic mapping, viz: Captain M. Hotine, R.E., Geographical Section, General Staff, Imperial Army. The quotation may be found on page 148, of the February 1930, issue of the Geographical Journal, Royal Geographical Society, London, England.

"Various simple and wilfully approximate methods of dealing with vertical aerial photographs have been evolved in order to solve the problem of topographical scales. We have for instance, the mosaic or composite photograph obtained by sticking individual prints together on a common base. In the hands of enthusiasts this Mosaic idea has from time to time been the subject of gross exaggeration and over statement."

"The truth is that it furnished a rapid means of obtaining a very detailed picture of an area of flat country. In undulating country it is less valuable on account of the difference in scale occurring at different levels, while in hilly country it cannot be compiled at all."

\section{ANALYTICAL SOLUTION}

Thirdly the same fundamental principles may be solved mathematically and the principal point traverse of the radial line method carried out in numerical terms rather than graphically as in 1 and 2 above. Unfamiliar formulas and lengthy complicated equations are used in this method which is known as the "Analytical solution of the problem of mapping from aerial photographs." In spite of the fact that those who have developed this procedure state that "the equations are simple;" to a forester they are difficult. Fortunately, the analytical solution can be applied readily without a thorough understanding of the derivations. 
This mathematical method is the most accurate solution of the problem of mapping from aerial photographs. Although at this time, to the knowledge of the writer, the method has never been tried out extensively on a commercial mapping job, it is felt that it has a definite place in the preparation of forest maps from vertical photographs. It does not seem probable that it will be used for complete mapping operations, but it will by its inherent accuracy, be of value in plotting a secondary control system.

The primary control system of any aerial mapping is the best available ground control supplemented if necessary by additional ground surveys. The map is then built up either by the mosaic or the radial line solution. It is suggested that the accuracy might $b$ strengthened by plotting a percentage of the lines by the analytical solution. The writer has in mind an area of 1500 square miles that has recently been photographed. The area is a long narrow strip of country. In order to save flying time the flight lines were flown parallel to the long axis. The interior ground control is weak, it is proposed to plot the flights having the poorest ties by the analytical method. These lines so protted will then, when adjusted to the ground surveys, be considered as part of the primary control.

The analytical solution has been treat:d in particular details because it je new in the realm of forest map preparation from aerial photographs. The writer feels that it should receive consideration by foresters when considering the most economic and consistently accurate method of building aerial maps.

The original derivation of the analytical solution is as old as terrestial photographic methods. It is during the past five years however that Earl Church, Associate Professor of Photogrammetry at Syracuse University has substituted original formulae and improved the mathematical procedure. The subject is completely covered in a series of bulletins prepared by Professor Church.

\section{PLOTTING MACHINES}

Finally we come to the intricate mechanism known as the plotting machine. This apparatus can be most briefly described as a mechanical means of carrying out the analytical solution of the radial line method. It was in an effort to avoid the laborious calculations of the analytical solution that the plotting machine was first conceived.

These machines are essentially an elaborate optical system that allows an operator, by trial and error, to set a stereoscopic pair in perfect correspondence. In other words to set one picture in relation to the other so that their positions are identical in every respect with the positions of the negatives at the instant of exposure. With the setting properly made, the machine then pro- 
vides, by means of a pantograph attachment, for the transfer of all topographic features from the photograph to a map sheet. The operator accomplishes this by following the outline of features and contours with an index known as a floating mark. This is but a crude description of a plotting machine but for the general introductory purpose of this paper it is sufficient.

The cost of plotting machines is excessive, running up to forty and fifty thousand dollars. They are cumbersome and time consuming in operation and are not mobile. It often requires a skilled operator a working day to complete the mapping of one overlap.

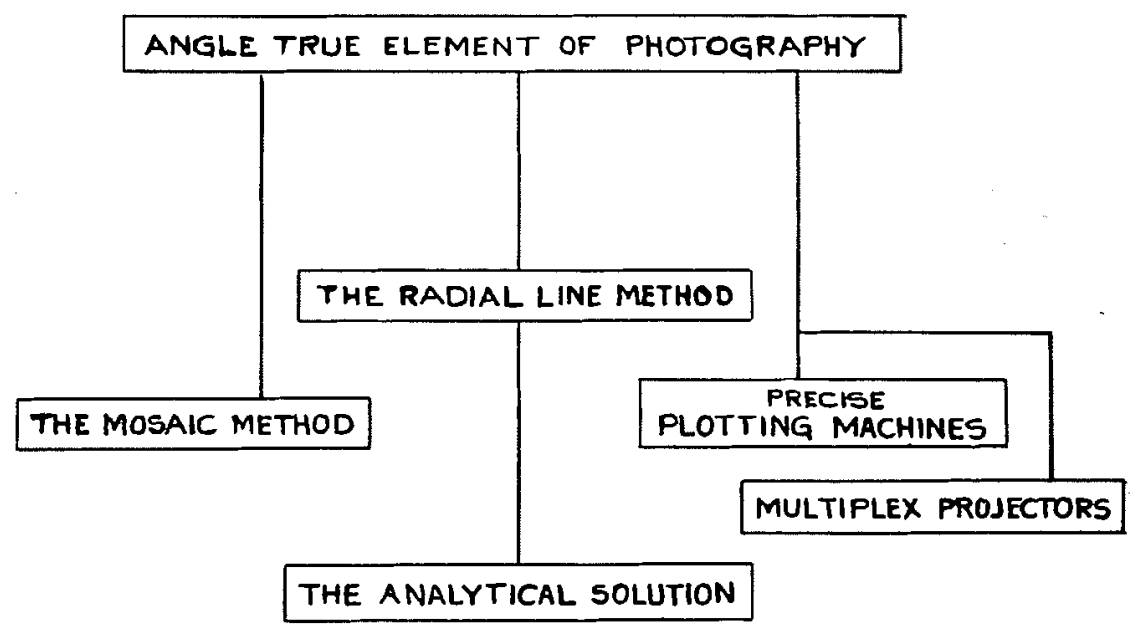

Fig. 2

Due to the fact that these machines are decidedly time consuming they have no place in the preparation of forest maps. They are mentioned here merely to complete the story of the evolution of the various mapping methods, all starting from the one fundamental principle.

There is a recent modified plotting machine employing the old camera plastic principle. This apparatus is by Zeiss of Germany and is known as the multiplex projector. Briefly it is a series of projectors which produce directly on the control layout a plastic image of the ground. The image projected in complimentary colors becomes plastic to the observer when viewed through eye glasses of the same complimentary colors. The machine is simple to operate, costs much less than the more elaborate plotting machine and is mobile. This multiplex will undoubtedly be the first of the plotting machines to have economic value to the forester. It is reputed to produce contour maps with an accuracy of $1 / 500$ of the exposure altitude of the picture whilst the more ex- 


\section{MAPPING METHODS}

pensive machine have an accuracy of $1 / 1500$ of the altitude. Its accuracy is quite consistent with that required for forest maps.

Figure two is introduced here to graphically show how the various mapping procedures are each related to the others.

The radial line method is the procedure of most interest and value to the forester. One of its strong points is its flexibility. It can and has been modified several different ways to suit the desired degree of accuracy required.

The mosaic method has a very limited usefulness. In fact it is the writer's opinion that mosaics whilst they have some advantages, cause a forester more trouble than their worth. The difference between a Mosaic and a line map is a subject in itself and does not, like the modifications referred to above, fall within the scope of this article.

In the mapping procedures that have been outlined the forester has, excepting the plotting machine, a choice of methods that can be adapted to any required degree of accuracy and allowable cost. It is undoubtedly true that most of the present users of aerial mapping are not conducting their efforts in the most economical manner solely because it is so difficult, due to the lack of literature, to become familiar with all the possibilities of aerial photography.

A few years ago the foresters in private employ, using aerial photography, were few and far between. Today they are numerous and are increasing rapidly. This increased interest in photography may be due largely to the efforts of the Topographical Surveys, who have made available to the public (Companies interested in using photographs) the large number of Government photographs that are on hand. These pictures are available through the functioning of a national lending library. Companies engaged in the management of forest lands can use these pictures for short periods for experimental purposes. By this routine such users have been able to develop methods of using photographs to suit their needs and subsequently have had their timber lands photographed by Commercial Aircraft Companies to the particular specifications that a forester requires. This is a form of Government Departmental effort that is to be highly recommended.

If you have problems in the use of aerial mapping it is suggested that you communicate them to the Survey Committee (sub-committees of the Forest Research Co-operation Committee).

Direct such communications to the Secretary, Mr. Roland Craig, Forest Service, Ottawa, or to the Chairman of the Committee, F. R. Wilcox, Canadian International Paper Company, Maniwaki.

Forest Survey costs may be cut in half by the use of aerial photographs to say nothing of their many other uses in Forest Management. 